\title{
Effects of Asphyxia on Cardiac Output and Organ Blood Flow in the Newborn Piglet
}

\author{
CHARLES T. ALWARD, JERRY B. HOOK, THOMAS A. HELMRATH, JOAN C. MATTSON, AND \\ MICHAEL D. BAILIE ${ }^{(17)}$ \\ Departments of Human Development, Physiology, Pharmacology and Pathology, Michigan State University, \\ East Lansing, Michigan, USA
}

\begin{abstract}
Summary
Experiments were performed on newborn piglets 6-96 hr of age. When the respiratory dead space was increased arterial $\mathrm{pO}_{2}$ decreased and $\mathrm{pCO}_{2}$ increased. During this time cardiac output was unchanged (Fig. 1), while heart rate, respiratory rate, and blood pressure increased (Figs. 2 and 3). After 90 min of asphyxia blood flow to the stomach and small and large intestines decreased. Changes in blood flow were associated with dilatation of segments of the small and large intestine with scattered areas of hemorrhage. Pathologic examination revealed scattered areas of mucosal necrosis (Fig. 6).
\end{abstract}

\section{Speculation}

Asphyxia causes both physiologic and pathologic changes in the gastrointestinal tract. Asphyxia appears to be one of the factors involved in the genesis of necrotizing enterocolitis.

Necrotizing enterocolitis is a frequent complication seen in newborn infants who have experienced perinatal stress $(1,10)$. Asphyxia is one of the stresses thought to be a factor in the generation of necrotizing enterocolitis $(10,12,14)$. It has been suggested that stress results in redistribution of cardiac output away from the mesenteric, renal, and peripheral vascular beds with a resultant relative increase in blood flow to the heart and brain (10). This redistribution of cardiac output protects the heart and brain which would rapidly suffer irreversible damage if deprived of adequate perfusion. Although many clinical reports appear to support this concept $(4,9,12,13)$, only Touloukian (14) actually measured the decrease in blood flow to the intestinal wall during asphyxia in 7 to 20 -day-old piglets. However, the level of asphyxia achieved in this study was more severe than that found in most clinical situations. Furthermore, the piglets studied were relatively mature compared to the human newborn. Therefore, it seemed important to determine effects of acute asphyxia on blood flow and cardiac output in the very young piglet. The present study was undertaken to determine change in blood flow to the gastrointestinal tract as well as other abdominal organs in newborn piglets subjected to moderate asphyxia.

\section{METHODS}

Experiments were performed on crossbred piglets obtained from the Swine Research Farm at Michigan State University. The piglets were born by spontaneous vaginal delivery and were studied between 6 and $96 \mathrm{hr}$ of age. At the time of the study they weighed between 1020 and $2180 \mathrm{~g}$.

Surgical procedures were performed under combined anesthesia with nitrous oxide:oxygen (4:1) and ketamine $(5 \mathrm{mg} / \mathrm{kg} \mathrm{im})$. A polyethylene catheter (PE-50) was advanced into the abdominal aorta from the right femoral artery for determination of blood pressure and heart rate, and for sampling arterial blood. A second catheter placed at the level of the right atrium via the left external jugular vein was used for the injection of Cardiogreen. Cardiac output measurements and radioactive microsphere injections were achieved through a third catheter (PE-90) placed in the ascending aorta by way of the left carotid artery. The position of all catheters was confirmed by inspection at the end of the experiment.

After suturing the skin incisions, the piglets were placed upright in a supporting sling and allowed to recover from anesthesia for $1 \mathrm{hr}$. During the surgical procedure and throughout the experiment the piglets were maintained at a body temperature of $38^{\circ}$ using a Mercor infant warmer. Rectal temperature was continuously monitored using a Yellow Springs thermister.

Two groups of piglets were studied. The nonstressed group was not subjected to any additional stresses following the surgical procedure. This group was utilized to evaluate whether changes occurred as a consequence of either the measuring techniques or the length of the experimental procedure. The second group of piglets was subjected to asphyxia. These piglets were intubated with a $3.5-\mathrm{mm}$ Portex endotracheal tube soon after the surgical procedure. After determination of baseline data, dead space (approximately $45 \mathrm{cc} / \mathrm{kg}$ ) was added to the endotracheal tube to produce the asphyxia.

In the nonstressed group data were collected for $1 \mathrm{hr}$ and then an injection of labeled $15 \mu \mathrm{m}$ microspheres (3M Company) was made into the carotid catheter. After an intermediate 30-min period, a second microsphere injection was made which was then followed by 60 additional min of data collection. The animals were killed by an iv injection of sodium pentobarbital.

The protocol was modified slightly in the asphyxiated group. Data were collected for $\mathbf{4 0} \mathrm{min}$ followed by the first microsphere injection, representing the control period for each experiment. The dead space was then added to the endotracheal tube. After $30 \mathrm{~min}$ of stabilization, a second microsphere injection was performed. Data collection proceeded for $1 \mathrm{hr}$ and then a third microsphere injection was made ( $90 \mathrm{~min}$ after asphyxia had been initiated). The dead space was then removed and data collected for $40 \mathrm{~min}$ representing the recovery period. The piglet was then killed in a similar manner.

During each period, cardiac output determinations were performed by injection of $0.15-0.40 \mathrm{ml}$ Cardiogreen solution (Hynson, Westcott, and Dunning, Inc.) containing $2.5 \mathrm{mg} / \mathrm{ml}$ dye into the right atrial catheter. Sampling from the ascending aorta was accomplished using a constant speed withdrawal pump at the rate of $4 \mathrm{ml} / \mathrm{min}$. Blood was withdrawn through a curvette densitometer (Waters Company), and the calibration and dye curve inscribed on a direct writing recording (Sargent-Welch recorder model SRG). After completion of the dye curve all blood was rapidly reinfused into the piglet. Withdrawal of blood did not change heart rate or blood pressure. The method of Hamilton et al. (2) was used to calculate cardiac output.

Heart rate and blood pressure were monitored continuously using a Statham pressure transducer $(\mathrm{P} 23 \mathrm{~dB})$ and recorded on a Grass Instruments polygraph. Respiratory rate was determined by 
direct observation. Arterial $\mathrm{pO}_{2}, \mathrm{pCO}_{2}$, and $\mathrm{pH}$ were measured using a Radiometer blood gas analyzer (model BMS 3). For statistical analysis $\mathrm{pH}$ values were converted to hydrogen ion concentration.

Organ blood flow was determined using $15-\mu \mathrm{m}$ microspheres labeled with ${ }^{51} \mathrm{Cr},{ }^{85} \mathrm{Sr}$, or ${ }^{141} \mathrm{Ce}$. The microspheres were thoroughly agitated in $0.5 \mathrm{ml} 20 \%$ dextran solution and injected rapidly into the carotid catheter. During injection blood was removed for one minute at a constant rate of $1.45 \mathrm{ml} / \mathrm{min}$ from the femoral artery catheter using a Harvard infusion withdrawal pump. This blood sample served as the standard flow rate for comparison with measured organs. Saline was infused to replace this blood loss. Additional injections were made during the course of the experiment with the order of the labeled microspheres being randomly varied. After all physiologic measurements the organs were removed, weighed, and placed in counting tlibes. Representative specimens from stomach and upper and lower gastrointestinal tracts were counted as well as the entire spleen, adrenals, and pancreas. The amount of radioactivity per specimen was counted in a Searle 1185 series three-channel gamma counter. After counting of representative specimens from stomach and upper and lower intestine, hemorrhagic, or discolored areas were selected and fixed in $10 \%$ buffered neutral formalin.

Specimen blood flow was calculated from the following formula: Flow $(\mathrm{ml} / \mathrm{min} / \mathrm{g})=\mathrm{q} / \mathrm{wt} \times \mathrm{f} / \mathrm{Q}$ where $\mathrm{q}=$ counts $\mathrm{per}$ specimen; $w t=$ tissue weight in grams; $F=$ withdrawal rate into arterial sampling syringe in $\mathrm{ml} / \mathrm{min} ; \mathrm{Q}=$ total counts in arterial syringe. Blood flow was expressed as milliliters per min per $\mathrm{m}^{2}$ surface area.

Data were analyzed using the student $t$-test and analysis of variance with the least significant differences test. The 0.05 level of probability was used as the criterion of significance.

\section{RESULTS}

Nine piglets were studied in the nonstressed group. No changes were seen in arterial $\mathrm{pO}_{2}, \mathrm{pCO}_{2}$, or $\mathrm{pH}$ during the course of the experiment. Cardiac output (Fig. 1), heart rate and respiratory rate (Fig. 2), blood pressure (Fig. 3), and organ blood flow were also unchanged in control animals (Fig. 4).

Fifteen piglets were studied in the respiratory distressed group. This experiment was divided into three periods-control, asphyxia, and recovery following the removal of the dead space. Each piglet acted as its own control permitting comparison of data from the asphyxia period and recovery period with the control period.

After the increase in respiratory dead space arterial $\mathrm{pO}_{2}$ decreased by $17 \pm 5 \mathrm{~mm} \mathrm{Hg}$ (from $55 \pm 9$ to $38 \pm 8 \mathrm{~mm} \mathrm{Hg}$ ) whereas $\mathrm{pCO}_{2}$ increased by $17 \pm 3 \mathrm{~mm} \mathrm{Hg}$ (from $44 \pm 13$ to $62 \pm 8 \mathrm{~mm}$ $\mathrm{Hg}$ ). The $\mathrm{pH}$ of the arterial blood decreased from $7.25 \pm 0.02$ to $7.03 \pm 0.03$. There was no change in cardiac output during the

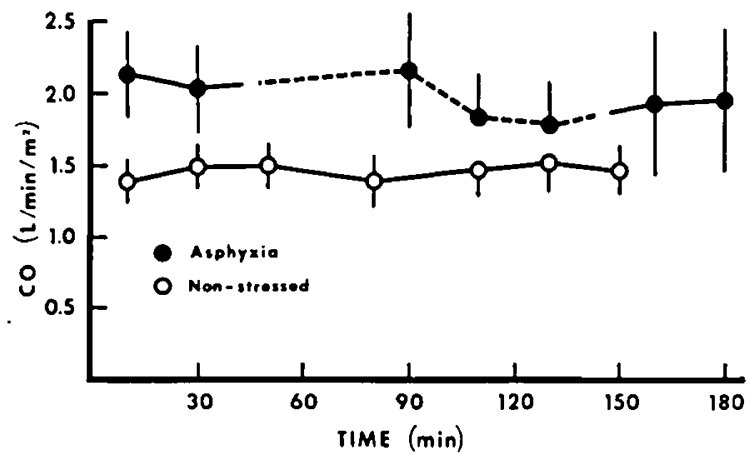

Fig. 1. Cardiac output in nonstressed piglets and piglets undergoing asphyxia. The period of asphyxia is shown by the dashed line. Asterisk $\left({ }^{*}\right)$ indicates values significantly different than control period $(P<0.05)$. Means \pm 1 SEM are shown.

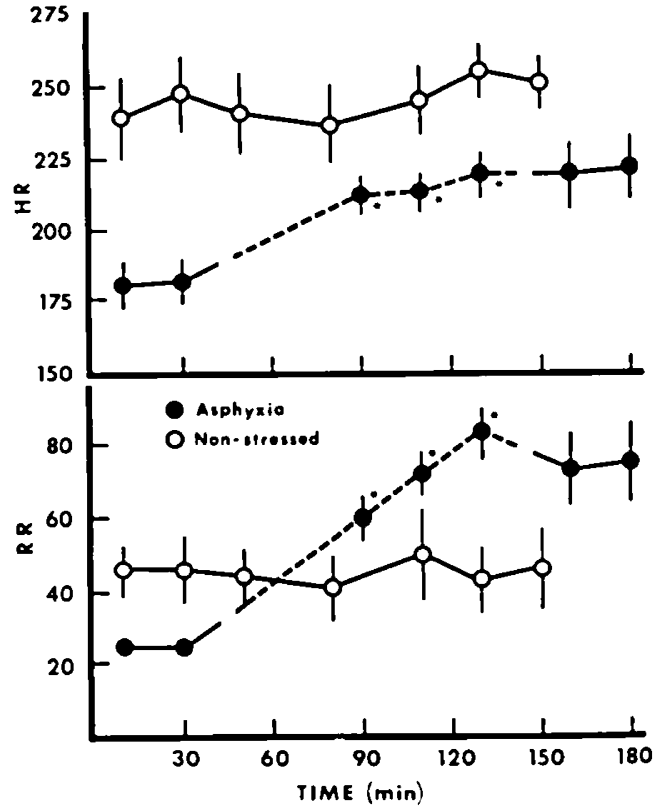

Fig. 2. Heart rate and respiratory rate in nonstressed piglets and piglets undergoing asphyxia. The period of asphyxia is shown by the dashed line. Asterisk (*) indicates values significantly different than control period ( $P$ $<0.05$ ). Means \pm 1 SEM are shown.

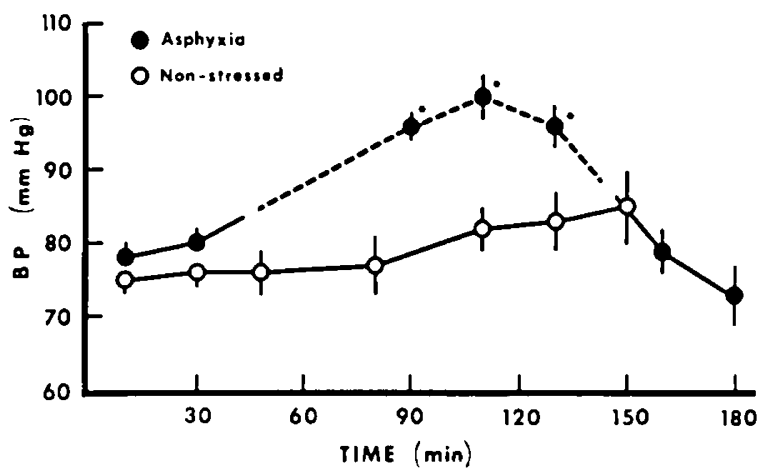

Fig. 3. Blood pressure and respiratory rate in nonstressed piglets and piglets undergoing asphyxia. The period of asphyxia is shown by the dashed line. Asterisk $\left(^{*}\right)$ indicates values significantly different than control period $(P<0.05)$. Means \pm 1 SEM are shown.

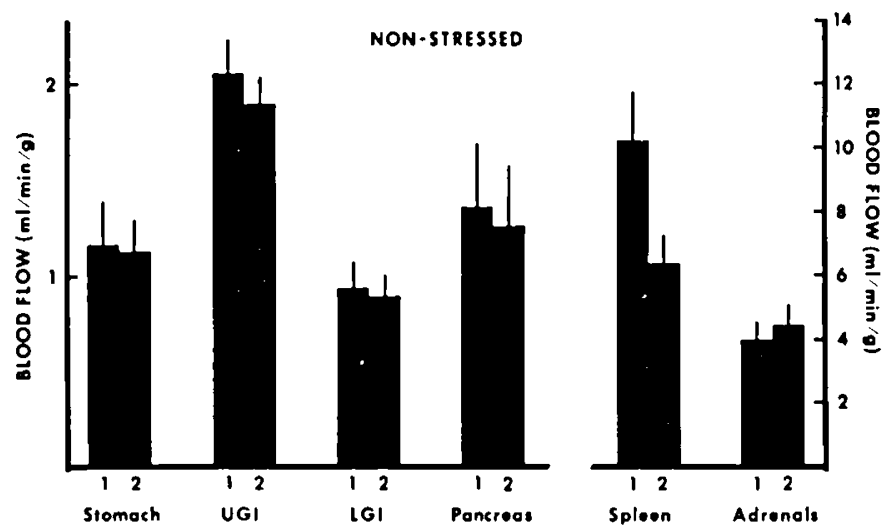

Fig. 4. Organ blood flow in nonstressed piglets. Time between first (1) and second (2) determination is $30 \mathrm{~min}$. Means \pm 1 SEM are shown.

period of stress (Fig. 1). Heart rate and respiratory rate increased during asphyxia and returned to control during recovery (Fig. 3 ).

After $30 \mathrm{~min}$ of respiratory distress, blood flow to the stomach, upper and lower intestinal tracts, and pancreas were unchanged 
while flow to the spleen had decreased and to the adrenals had increased (Fig. 5). Asphyxia for 90 min resulted in decreased flow to the stomach, upper and lower intestinal tracts, pancreas, and spleen, whereas flow to the adrenals had returned to control level. Upon visualization of the abdominal contents in the distressed animals segments of the small and large intestine were clearly dilated with scattered areas of hemorrhage throughout the entire length of the intestine. Similar findings were not observed in any of the nonstressed animals.

Pathologic examination of the intestine revealed scattered areas of mucosal necrosis (Fig. 6). Interspersed between the necrotic foci was normal appearing tissue. At the margin of the patches of frankly necrotic intestinal mucosa, intact epithelial cells demonstrated an unusual accumulation of large globular masses of homogeneous eosinophilic material within their cytoplasm. This

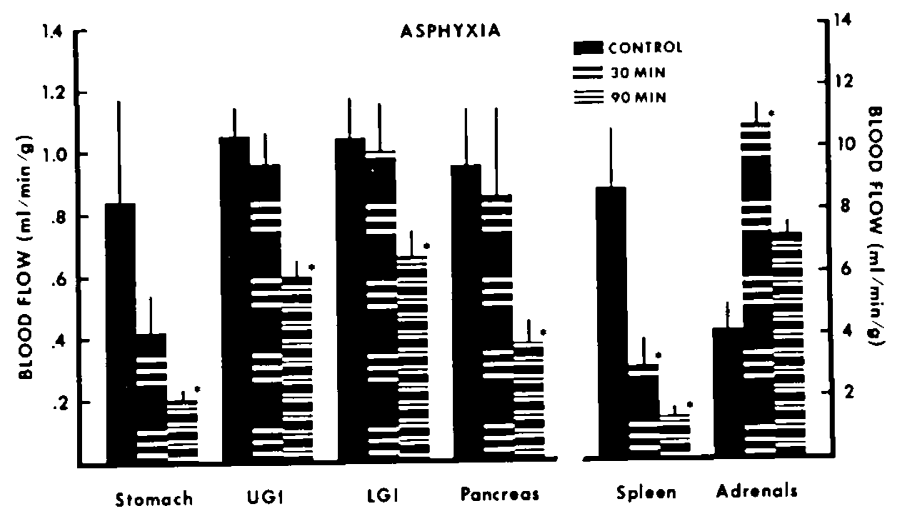

Fig. 5. Organ blood flow in asphyxiated piglets during control period and following $30 \mathrm{~min}$ and $90 \mathrm{~min}$ of asphyxia. Asterisks (*) indicates values significantly different than control period $(P<0.05)$. Means \pm 1 SEM are shown. material may represent an abnormal accumulation of secretory products. In many areas damaged intestinal villi were covered by cellular debris in a proteinacious matrix.

\section{DISCUSSION}

There appear to be at least three components essential for the development of necrotizing enterocolitis: 1) the presence of bacteria in the gastrointestinal tract; 2) availability of metabolic substrate related to feeding; and 3) injury to the intestinal mucosa (10). Although it has been suggested that intestinal mucosa injury occurs by several different mechanisms $(3,5,8,10)$, asphyxia is mentioned most frequently. Asphyxia is defined as anoxia with carbon dioxide retention resulting from failure of respiration, leading to respiratory and metabolic acidosis (12). Conditions associated with asphyxia are fetal distress with low Apgar scores, respiratory distress syndromes, and apnea.

In the present investigation an increase in respiratory dead space was utilized to mimic the state of neonatal asphyxia. The addition of dead space resulted in a decrease in $\mathrm{pO}_{2}$ with an increase in $\mathrm{pCO}_{2}$ and fall in $\mathrm{pH}$. The results of the studies in the nonstressed piglet document the stability of the experimental model. Cardiac output and heart rate (Fig. 1) and blood pressure (Fig. 2) were unchanged during the 150-min observation on the nonstressed animals. However, differences in heart rate; respiratory rate (Fig. 1) and organ blood flow (Figs. 4 and 5) between stressed and nonstressed animals were noted during control periods. We do not have an explanation for such differences. Inasmuch as the experiments were conducted over a period of 18 months, differences between the two groups may be related to seasonal variations or other undefined time related factors. Since the asphyxiated piglets served as their own controls comparison of the periods of asphyxia and recovery were made with the control period.

The relationship of asphyxia to blood flow to the gastrointestinal tract in the newborn piglets was previously studied by Touloukian

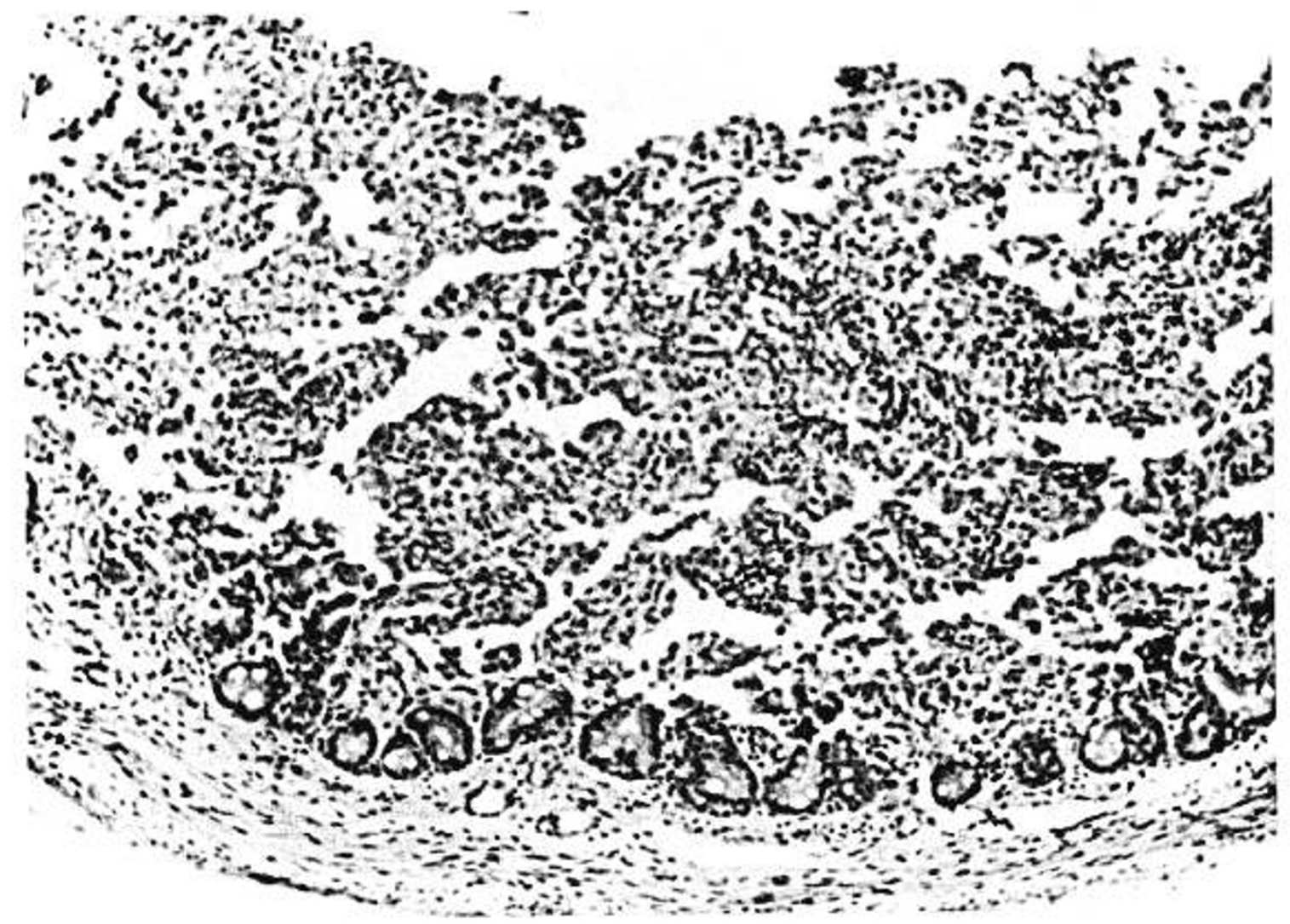

Fig. 6. Jejunum: Necrosis of intestinal mucosa as demonstrated by total loss of normal villus architecture. Intestinal smooth muscle is not affected. Magnification $\times 10$. 
(14). In 7- to 20-day-old piglets asphyxiated until respiration and heart rate were depressed below 15 and $40 \mathrm{~min}$, respectively, gastrointestinal blood flow decreased. Cardiac output was unchanged during asphyxia and increased during recovery (14).

In the present study, piglets 6-96 hours old were utilized since these animals were clearly in the neonatal age range. Increasing the respiratory dead space resulted in compensatory increase in heart rate, respiratory rate, and blood pressure (Figs. 3 and 4). Cardiac output was unchanged during the procedure (Fig. 1), indicating a decrease in stroke volume. Blood flow to the gastrointestinal tract was unchanged after $30 \mathrm{~min}$ but had decreased by 90 min of respiratory distress (Fig. 5). These data suggest that normal distribution of cardiac output is maintained to those organs studied for at least $30 \mathrm{~min}$ after induction of asphyxia. Later, cardiac output is apparently redistributed away from less vital organs to the heart and brain, although flow to these latter organs were not measured in this study. Pathologic evaluation of tissue obtained from the gastrointestinal tract revealed submucosal and mucosal vascular congestion suggesting blood flow was restored to the ischemic areas during the recovery period (Figs. 6 and 7). The focal interstitial hemorrhage supports the suggestion that the 90 min of asphyxia is sufficient to cause capillary damage with resultant interstitial hemorrhage as flow is re-established.

Factors other than intestinal ischemia could contribute to the redistribution of cardiac output and resultant necrotizing enterocolitis. Decreased flow to the adult pancreas during shock results in the release of myocardial depressant factor $(6,7,11)$. Myocardial depressant factor causes direct cardiodepressant effects, vasoconstrictor effects on splanchnic blood vessels, and depressed phagocytic properties of the reticuloendothelial system.

Significant changes in blood flow to the spleen and adrenal glands appeared to take place before changes in flow to other organs studied. The reason for this difference is not clear. The physiologic significance of the changes observed will require additional study.

Thus, the present study suggests that asphyxia causes no immediate changes in cardiac output or blood flow to the gastrointestinal tract. It is possible that changes not detectable by the present methods did take place. The more prominent changes in organ flow observed at the later time make it appear that the duration of asphyxia as well as other undefined factors are important in the pathogenesis of necrotizing enterocolitis.

\section{REFERENCES AND NOTES}

1. Frantz, I. D., L'Houreux, P., Engel, R. R., and Hunt, C. E.: Necrotizing enterocolitis. J. Pediat., 86: 259 (1975).

2. Hamilton, W. F., Moore, J. W., Kinsman, J. M., and Spurling, R. G.: Studies on the circulation. IV. Further analysis of the injection method, and of changes in hemodynamics under physiological and pathological conditions. Amer. J. Physiol., 99: 534 (1932).

3. Hardy, J. D., Savage, T. R., and Shirodaria, C.: Intestinal perforation following exchange transfusion. Amer. J. Dis. Child., J24: 136 (1972).

4. Joshi, V. V., Winston, Y. E., and Kay, S.: Neonatal necrotizing enterocolitis. Amer. J. Dis. Child., 126: 113 (1973).

5. Kitterman, J. A.: Necrotizing enterocolitis in the newborn infant, 68th Ross Conference on Pediatric Research, p. 38 (1975).

6. Lefer, A. M.: Role of a myocardial depressant factor in the pathogenesis of circulatory shock. Fed. Proc., 29: 1836 (1970).

7. Lefer, A. M.: Role of a myocardial depressant factor in shock states. Modern Concepts Cardiovasc. Dis., 42: 59 (1973).

8. Livaditis, A., Wallgren, G., and Foxelius, G.: Necrotizing enterocolitis after catheterization of the umbilical vessels. Acta Pediat. Scand., 63: 277 (1974).

9. Lloyd, R.: The etiology of gastrointestinal perforation in the newborn. J. Pediat. Surg., 4: 77 (1969).

10. Santulli, T. V., Schullinger, J. N., Heird, W. C., Gongaware, R. D., Wigger, J., Barlow, B., Blanc, W. A., and Berden, W. E.: Acute necrotizing enterocolitis in infancy: A review of 64 cases. Pediatrics, 55: 376 (1975).

11. Spath, J. A., Gorczynski, R. J., and Lefer, A. M.: Pancreatic perfusion in the pathophysiology of hemorrhagic shock. Amer. J. Physiol., 266: 443 (1974).

12. Rowe, M. I.: Necrotizing enterocolitis in the newborn infant, 68 th Ross Conference on Pediatric Research, p. 33 (1975).

13. Touloukian, R. J.: Gastric ischemia: The primary factor in neonatal perforation Clin. Pediat., 12: 219 (1973).

14. Touloukian, R. J., Posch, J. N., and Spencer, R.: The pathogenesis of ischemic gastroenterocolitis of the neonate: Selective gut mucosal ischemia in asphyxiated neonatal piglets. J. Pediat. Surg., 7: 194 (1972).

15. The authors wish to express their gratitude to Ms. Toni Thiel, Ms. Sara Patten, and Mr. Keith Crosslan for excellent technical assistance.

16. This research was supported by NIH Grant HD 06290 from the NICHHD. Dr. Alward was a postdoctoral fellow of the National Kidney Foundation and Kidney Foundation of Michigan.

17. Requests for reprints should be addressed to: Dr. Michael D. Bailie, Department of Human Development, B342 Life Sciences, Michigan State University, East Lansing, MI 48824 (USA).

18. Received for publication July $11,1977$.

19. Accepted for publication October 18, 1977. 